\title{
Impact of Variable Air Flow Rate in Energy Smart Window Curtains, on The Total Net Heat Gain- Analytical Solutions
}

\author{
Carl-Eric Hagentoft ${ }^{* *, 1}$, Ali Naman Karim ${ }^{1}$ \\ ${ }^{1}$ Department of Architecture and Civil Engineering, Building Physics Modelling, \\ Chalmers University of Technology, Sweden \\ **Corresponding author. E-mail address: Carl-Eric.Hagentoft@chalmers.se
}

\begin{abstract}
In this paper, the impact of variable air flow rate on the performance of the solar collector function of the Climate Curtain is evaluated. Climate Curtain is a new type of window curtain developed by the company Climate Curtains AB in Sweden. This curtain consists of several layers of stagnant air, and the solar collector function of this curtain captures some part of solar radiation striking the window; warmer air is forced into the room by fans mounted inside the curtain. The paper presents general and handy formulas which can be used to determine the impact of the curtain and its solar collector function, on the total net heat gain in the room. The solution presented is applicable on similar vertical air gaps to evaluate energy performance.
\end{abstract}

\section{Introduction}

According to the international Energy Agency, buildings account for approximately $40 \%$ of the global demand for energy (Zhao and Magoulès, 2012). In most of the cases windows are the weak spots of the building envelope concerning the energy performance, and for heated buildings, windows stand for a tremendous amount of energy losses. At the moment, several new and innovative types of energy efficient windows are developed and available on market. However, there are still a large number of old buildings all around the world, where windows with high U-values are used. Additionally, many buildings such as schools, offices and recreational homes are, on average, used actively for only a fraction of a year. By covering windows with the Climate Curtains, when buildings are empty, the U-values of windows can be improved without replacing the windows by new and expensive ones.

In this paper the energy efficiency, and in particular the positive impact of the solar collector function of the Climate Curtain is in focus.

\section{Design of the Climate Curtains}

In the design of the Climate Curtains, a curtain rod with 8 layers of textile, creating 7 layers of stagnant air with an approximate width of $10-15 \mathrm{~mm}$, are used.
Two different designs of the Climate Curtains have been presented by the developer company. In the default design, the air gaps of the curtain are used as additional thermal insulation for the window and the upper and lower ledges are completely air tight (Karim, 2018). In the second conceptional design of the curtain, one additional feature is included. Figure 1 shows the details of the design of the Climate Curtain studied in this paper. As seen, the external black surface is utilized to capture a fraction of solar radiation striking the window and curtain. The heated air is circulated back into the room via air ducts in the lower ledge of the curtain. The circulation of heated air is accelerated by small fans positioned in the upper ledge, controlled by a differential temperature control module, one temperature sensor inside the outermost air layer of the curtain and one sensor inside the room. The curtain can be designed in various dimensions. For the curtain of default design, a surface to surface resistance of $0.65 \mathrm{~m}^{2} \mathrm{~K} / \mathrm{W}$, and for the curtain with a solar collector function, a resistance of $0.38 \mathrm{~m}^{2} \mathrm{~K} / \mathrm{W}$ has been estimated experimentally (Karim, 2018). A more comprehensive description of the Climate Curtains is presented in (Karim, 2018) and (Karim and Hagentoft, 2019).

\section{Methodology}

The methodology used in this paper, to analyse the effect of air flow rate on the performance of the solar collector function of the curtain, is a quantitative approach consisting of a set of analytical formulas. The approach used in this paper is utilizing the superposition technique to divide the complex problem into two separate processes. Once these two process are solved separately, the final solution includes the merged solution of the two processes.

\section{Analyzed system- Model description}

To analyze the impact of the air flow rate created by fans, in the outermost air gap of the curtain, on the total net heat gain in a room, a 2D model of a window construction, as shown in Figure 2 is studied. The model is studied for two separate cases of convection, natural convection when warmer air is trans- 


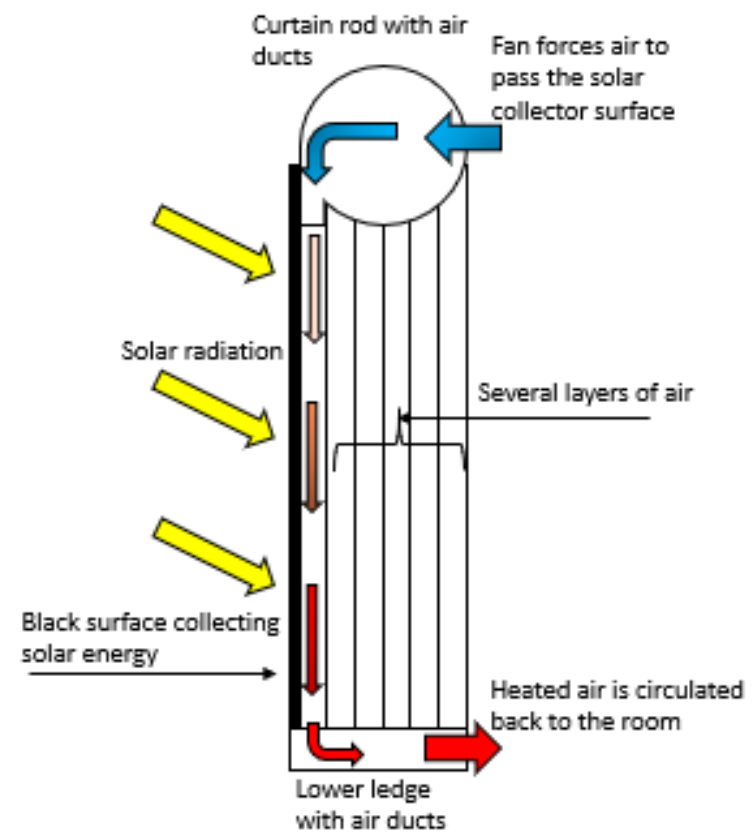

Figure 1: Schematic, not in scale, showing the design of Climate Curtain with solar collector function.

ferred into the room due to temperate differences, and forced convection due to the fans.

The studied system, consists of a Climate Curtain and the corresponding black screen for solar collection, a window and the air gap created between the window and the curtain. $\mathrm{R}_{\mathrm{f}}\left[\mathrm{m}^{2} \mathrm{~K} / \mathrm{W}\right]$ corresponds to the thermal resistance between the black screen to external temperature. $R_{\mathrm{g}}\left[\mathrm{m}^{2} \mathrm{~K} / \mathrm{W}\right]$ represents the thermal resistance between the air gap to internal temperature. $\mathrm{H}[\mathrm{m}]$ is the height of the window and thus the length of the air path. The air flow rate inside the air gap is denoted by $\mathrm{q}_{\mathrm{a}}\left[\mathrm{m}^{3} / \mathrm{ms}\right]$, while the absorbed solar radiation at the screen is denoted by $\mathrm{q}_{\mathrm{sol}}\left[\mathrm{W} / \mathrm{m}^{2}\right] . \quad \mathrm{T}_{\mathrm{e}}\left[{ }^{\circ} \mathrm{C}\right]$ and $\mathrm{T}_{\mathrm{i}}\left[{ }^{\circ} \mathrm{C}\right]$ are the external and internal air temperatures respectively.

\section{Forced convection}

For the case of forced convection, created by fans, the system is handled by solving two separate processes, using superposition technique. The air flow in the gap is the same and constant in both two processes. In the first process no absorption of solar radiation is assumed. Beside the indoor and outdoor temperatures, $\mathrm{T}_{\mathrm{i}}$ and $\mathrm{T}_{\mathrm{e}}$, a new balance temperature, $\mathrm{T}_{\mathrm{b}}$, is defined for the air temperature in the whole air gap. $\mathrm{T}_{\mathrm{b}}$ is obtained at no air flow and is also assumed as inlet air temperature of the air gap. The balance temperature is defined as (1)(Hagentoft, 2001):

$$
T_{b}=\frac{R_{f} \cdot T_{i}+R_{g} \cdot T_{e}}{R_{f}+R_{g}}=\frac{\frac{T_{i}}{R_{g}}+\frac{T_{e}}{R_{f}}}{\frac{1}{R_{f}}+\frac{1}{R_{g}}}
$$

In the second process, the air inlet temperature to the gap is $\left(\mathrm{T}_{\mathrm{i}}-\mathrm{T}_{\mathrm{b}}\right)$, while the indoor and outdoor temperatures equal to zero. In this process it is assumed that the absorbed solar radiation is instantly

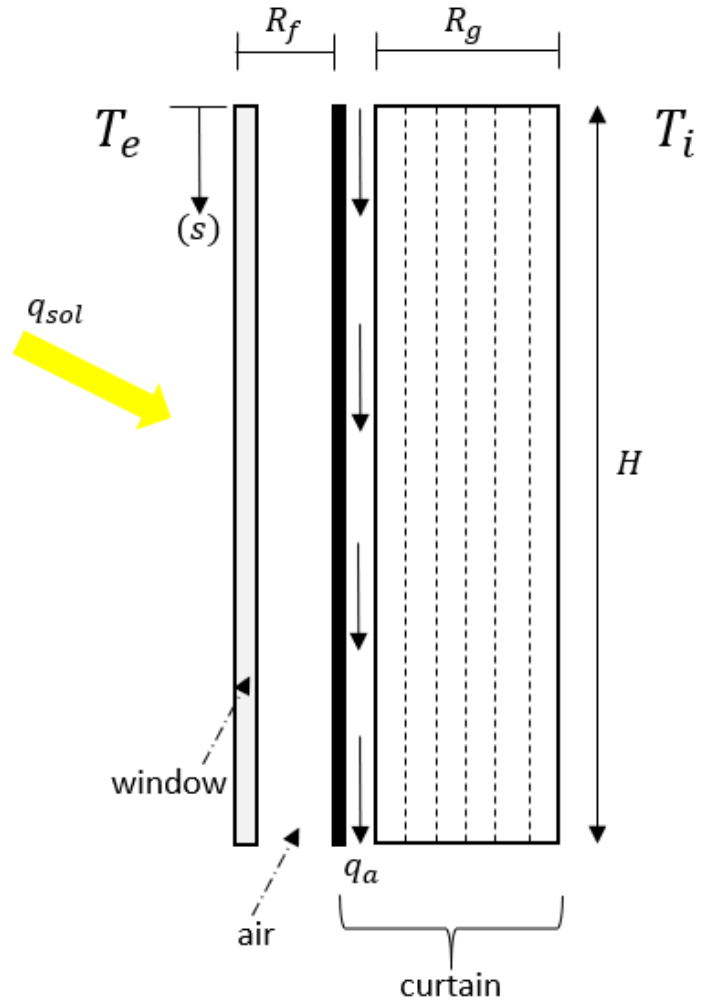

Figure 2: Model to be analyzed, including a curtain, a window and the air gap in between.

and totally transferred to air by a convection process. The following energy balance equation (2) along the air gap is to be handled:

$$
\frac{\mathrm{dT}(\mathrm{s})}{\mathrm{ds}} \cdot \mathrm{q}_{\mathrm{a}} \cdot \rho_{\mathrm{a}} \cdot \mathrm{c}_{\mathrm{pa}}=\mathrm{q}_{\mathrm{sol}}-(\mathrm{T}(\mathrm{s})-0) \cdot\left(\frac{1}{\mathrm{R}_{\mathrm{f}}}+\frac{1}{\mathrm{R}_{\mathrm{g}}}\right)
$$

Where $\rho_{\mathrm{a}}$ and $\mathrm{c}_{\mathrm{pa}}$ are air density $\left[\mathrm{kg} / \mathrm{m}^{3}\right]$ and specific heat capacity $[\mathrm{J} / \mathrm{kgK}]$ respectively.

The energy balance equation can be rewritten as (3):

$$
\frac{\mathrm{dT}(\mathrm{s})}{\mathrm{ds}}=\frac{\mathrm{q}_{\mathrm{sol}}}{\mathrm{l}_{\mathrm{c}} \cdot\left(\frac{1}{\mathrm{R}_{\mathrm{f}}}+\frac{1}{\mathrm{R}_{\mathrm{g}}}\right)}-\frac{(\mathrm{T}(\mathrm{s})-0)}{\mathrm{l}_{\mathrm{c}}}
$$

$l_{c}$ is the characteristic length parameter of the air gap and is defined as (4):

$$
l_{\mathrm{c}}=\frac{\mathrm{q}_{\mathrm{a}} \cdot \rho_{\mathrm{a}} \cdot \mathrm{c}_{\mathrm{pa}}}{\frac{1}{\mathrm{R}_{\mathrm{f}}}+\frac{1}{\mathrm{R}_{\mathrm{g}}}}
$$

Adding the solutions for the two processes by superpositioning, the solution for the total system (3) becomes (5):

$$
\begin{aligned}
\mathrm{T}(\mathrm{s}) & =\mathrm{T}_{\mathrm{b}}+\mathrm{T}_{\mathrm{bs}} \cdot\left(1-\mathrm{e}^{-\mathrm{s} / \mathrm{l}_{\mathrm{c}}}\right)+\left(\mathrm{T}_{\mathrm{i}}-\mathrm{T}_{\mathrm{b}}\right) \cdot \mathrm{e}^{-\mathrm{H} / \mathrm{l}_{\mathrm{c}}} \\
\mathrm{T}_{\mathrm{bs}} & =\frac{\mathrm{q}_{\mathrm{s}}}{\frac{1}{\mathrm{R}_{\mathrm{f}}}+\frac{1}{\mathrm{R}_{\mathrm{g}}}}
\end{aligned}
$$

Where $T_{b s}$ is an additional balance temperature due to solar radiation.

The second term in (5) represents the increase in 
temperature in the air gap due to solar radiation and the first and third terms are the declination due to regular adoption to the balance temperature in the case without solar radiation.

\section{Heat gain in the room}

The net heat gain is a result of the heat that flows out through the window and heat that is convectively recovered to the room. $\mathrm{Q}_{\mathrm{in}}[\mathrm{W} / \mathrm{m}]$ is the heat gain per meter window in horizontal direction and is defined as (6):

$$
\mathrm{Q}_{\text {in }}=\mathrm{Q}_{\text {conv }}-\mathrm{Q}_{\text {cond }}
$$

Where

$$
\begin{gathered}
\mathrm{Q}_{\text {conv }}=\mathrm{q}_{\mathrm{a}} \cdot \rho_{\mathrm{a}} \cdot \mathrm{c}_{\mathrm{pa}} \cdot\left(\mathrm{T}(\mathrm{H})-\mathrm{T}_{\mathrm{i}}\right) \\
\mathrm{Q}_{\text {cond }}=\frac{1}{\mathrm{R}_{\mathrm{g}}} \int_{0}^{\mathrm{H}}\left(\mathrm{T}_{\mathrm{i}}-\mathrm{T}(\mathrm{s})\right) \mathrm{ds}
\end{gathered}
$$

With the solution for the air gap temperature (5) inserted in (8) and after some algebra, it can be rewritten as follow:

$$
\mathrm{Q}_{\text {cond }}=\frac{1}{\mathrm{R}_{\mathrm{g}}} \cdot\left(\mathrm{T}_{\mathrm{i}}-\mathrm{T}_{\mathrm{bs}}-\mathrm{T}_{\mathrm{b}}\right) \cdot\left(\mathrm{H}-\mathrm{l}_{\mathrm{c}} \cdot\left(1-\mathrm{e}^{-\mathrm{s} / \mathrm{l}_{\mathrm{c}}}\right)\right)
$$

Similarly the equation for $\mathrm{Q}_{\text {conv }}$ becomes:

$$
\begin{aligned}
\frac{\mathrm{Q}_{\text {conv }}}{\mathrm{q}_{\mathrm{a}} \cdot \rho_{\mathrm{a}}}= & \mathrm{T}_{\mathrm{bs}} \cdot\left(1-\mathrm{e}^{-\mathrm{H} / \mathrm{l}_{\mathrm{c}}}\right)+\mathrm{T}_{\mathrm{b}} \cdot\left(1-\mathrm{e}^{-\mathrm{H} / \mathrm{l}_{\mathrm{c}}}\right) \\
& +\mathrm{T}_{\mathrm{i}} \cdot \mathrm{e}^{-\mathrm{H} / \mathrm{l}_{\mathrm{c}}}-\mathrm{T}_{\mathrm{i}}
\end{aligned}
$$

For the case of very low air flow rate $\left(l_{\mathrm{c}} \approx 0\right)$ in the air gap:

$$
\begin{aligned}
\mathrm{Q}_{\text {in.low }} & =\mathrm{Q}_{\text {conv }}-\mathrm{Q}_{\text {cond }} \approx-\mathrm{Q}_{\text {cond }} \\
& =\frac{\mathrm{H}}{\mathrm{R}_{\mathrm{g}}} \cdot\left(\mathrm{T}_{\mathrm{bs}}+\mathrm{T}_{\mathrm{b}}-\mathrm{T}_{\mathrm{i}}\right)
\end{aligned}
$$

For the case of very high air flow rate $\left(l_{c}>>0\right)$ in the air gap:

$$
\begin{aligned}
& \mathrm{Q}_{\text {cond.high }} \approx \\
& \frac{1}{\mathrm{R}_{\mathrm{g}}} \cdot\left(\mathrm{T}_{\mathrm{i}}-\mathrm{T}_{\mathrm{bs}}-\mathrm{T}_{\mathrm{b}}\right) \cdot\left[\mathrm{H}-\mathrm{l}_{\mathrm{c}} \cdot\left(1-\left(1-\frac{\mathrm{H}}{\mathrm{l}_{\mathrm{c}}}\right)\right)\right] \\
= & \frac{1}{\mathrm{R}_{\mathrm{g}}} \cdot\left(\mathrm{T}_{\mathrm{i}}-\mathrm{T}_{\mathrm{bs}}-\mathrm{T}_{\mathrm{b}}\right) \cdot\left[\mathrm{H}-\mathrm{l}_{\mathrm{c}} \cdot\left(\frac{\mathrm{H}}{\mathrm{l}_{\mathrm{c}}}\right)\right]=0
\end{aligned}
$$

And

$$
\mathrm{Q}_{\text {conv.high }}=\left(\frac{1}{\mathrm{R}_{\mathrm{g}}}+\frac{1}{\mathrm{R}_{\mathrm{f}}}\right) \cdot \mathrm{H} \cdot\left(\mathrm{T}_{\mathrm{bs}}+\mathrm{T}_{\mathrm{b}}-\mathrm{T}_{\mathrm{i}}\right)
$$

Now, by using the expressions for $\mathrm{Q}_{\text {conv.high }}$ and $\mathrm{Q}_{\text {cond.high }}$ and inserting the expressions for balance temperatures, (1) and (5), $\mathrm{Q}_{\text {in.high }}$ for the case of very high air flow rate becomes:

$$
\begin{aligned}
\mathrm{Q}_{\text {in.high }} & =\mathrm{Q}_{\text {conv.high }}-\mathrm{Q}_{\text {cond.high }} \approx \mathrm{Q}_{\text {conv.high }} \\
& =\mathrm{H} \cdot\left(\mathrm{q}_{\mathrm{sol}}-\frac{\mathrm{T}_{\mathrm{i}}-\mathrm{T}_{\mathrm{e}}}{\mathrm{R}_{\mathrm{f}}}\right)
\end{aligned}
$$

As seen in (14), the heat flow represents the total absorbed solar energy minus the reduction due to heat conduction outwards and through the window construction. The temperature in the air gap is always equal to $\mathrm{Ti}$.

Using the results obtained in (9) and (10), the general expression for $\mathrm{Q}_{\text {in }}$ in (6) can be reformulated to:

$$
\mathrm{Q}_{\mathrm{in}}=\left(\mathrm{T}_{\mathrm{bs}}+\mathrm{T}_{\mathrm{b}}-\mathrm{T}_{\mathrm{i}}\right) \cdot\left[\frac{\mathrm{l}_{\mathrm{c}}}{\mathrm{R}_{\mathrm{f}}} \cdot\left(1-\mathrm{e}^{-\mathrm{H} / \mathrm{l}_{\mathrm{c}}}\right)+\frac{\mathrm{H}}{\mathrm{R}_{\mathrm{g}}}\right]
$$

The general expression for $\mathrm{Q}_{\text {in }}$ can be further simplified after some algebra to:

$$
\begin{aligned}
Q_{\text {in }}= & {\left[q_{\text {sol }}-\frac{T_{i}-T_{e}}{R_{f}}\right] \cdot H \cdot \frac{R_{f}}{R_{g}+R_{f}} } \\
& \cdot\left[\frac{R_{g}}{R_{f}} \cdot \frac{l_{c}}{H} \cdot\left(1-e^{-H / l_{c}}\right)+1\right]
\end{aligned}
$$

The final formula for $Q_{\text {in }}(16)$ is in consistent with (11) and (14), i.e the two extreme cases of very high and low (zero) flow rates.

\section{Natural convection}

For the case of natural convection, i.e when fans are excluded from the curtain system and the additional heat from the solar collector function is transferred due to stack effect, the analysis is based on one mean temperature in the air gap. The estimation of the mean temperature in the air gap is initially based on a guessed airflow rate. The calculated mean temperature represents a pressure difference due to the differences in temperatures. By multiple iterations a consistent air flow rate can be finally obtained. The pressure difference due to stack effect is given by (17) (Straube, 2002):

$$
\begin{aligned}
\Delta \mathrm{P} & =\mathrm{H} \cdot 3456 \cdot\left(\frac{1}{\mathrm{~T}_{\mathrm{i}}}-\frac{1}{\overline{\mathrm{T}}}\right. \text { airgap } \\
\overline{\mathrm{T}}_{\text {airgap }} & =\frac{1}{\mathrm{H}} \cdot \int_{0}^{\mathrm{H}} \mathrm{T}(\mathrm{s}) \mathrm{ds}
\end{aligned}
$$

Where temperatures in (17) are in Kelvin. Dicks formula gives the air flow rate, $\mathrm{R}_{\mathrm{a}}\left[\mathrm{m}^{3} / \mathrm{ms}\right]$, and for one meter of window in horizontal direction and for a hole area of $\mathrm{A}_{1}\left[\mathrm{~m}^{2} / \mathrm{m}\right]$, the air flow rate $\mathrm{q}_{\mathrm{a}}\left[\mathrm{m}^{3} / \mathrm{ms}\right]$ becomes (Hagentoft, 2001):

$$
\mathrm{q}_{\mathrm{a}}=\mathrm{A}_{1} \cdot 0.84 \cdot \sqrt{\Delta \mathrm{P}}
$$

By using the previous formula presented in (5), and with an air inlet temperature equal to $T_{i}$, the expression for $\overline{\mathrm{T}}_{\text {airgap }}$ can be further developed as follow: 
$\overline{\mathrm{T}}_{\text {airgap }}=\mathrm{T}_{\mathrm{b}}+\mathrm{T}_{\mathrm{bs}}-\frac{\mathrm{l}_{\mathrm{c}}}{\mathrm{H}} \cdot\left(\mathrm{T}_{\mathrm{bs}}+\mathrm{T}_{\mathrm{b}}-\mathrm{T}_{\mathrm{i}}\right) \cdot\left(1-\mathrm{e}^{-\mathrm{H} / \mathrm{l}_{\mathrm{c}}}\right)$

Comparison of the net heat gain with and without a curtain and its solar collector function

In order to evaluate the performance of the solar collector function of the Climate Curtain, a comparison of the net heat gain between two cases, one case of only a window without a curtain, and one case of a window, a curtain and its solar collector function is made.

For the first case of only a window, the heat gain for one meter in the horizontal direction of the window, $\mathrm{Q}_{\text {in.window }}[\mathrm{W}]$, is calculated by $(20)$

$$
\mathrm{Q}_{\text {in.window }}=\mathrm{q}_{\mathrm{sol}} \cdot 1 \cdot \mathrm{H}-\frac{1 \cdot \mathrm{H}}{\mathrm{R}_{\mathrm{f}}} \cdot\left(\mathrm{T}_{\mathrm{i}}-\mathrm{T}_{\mathrm{e}}\right)
$$

The heat gain for the second case of both a window and a curtain, $Q_{\text {in.curtain }}[\mathrm{W}]$, is estimated by (16). $\eta[-]$ is the relation between the heat gains from the two cases explained above, and is a measure of efficiency for the solar collector function of the Climate Curtain.

$\eta=\frac{\mathrm{Q}_{\text {in.curtain }}}{\mathrm{Q}_{\text {in.window }}}=\frac{\mathrm{R}_{\mathrm{f}}}{\mathrm{R}_{\mathrm{f}}+\mathrm{R}_{\mathrm{g}}} \cdot\left[\frac{\mathrm{R}_{\mathrm{g}}}{\mathrm{R}_{\mathrm{f}}} \cdot \frac{\mathrm{l}_{\mathrm{c}}}{\mathrm{H}} \cdot\left(1-\mathrm{e}^{-\mathrm{H} / \mathrm{l}_{\mathrm{c}}}\right)+1\right]$

For the case of very low air flow rate $\left(l_{\mathrm{c}} \approx 0\right)$ in the air gap:

$$
\eta=\frac{\mathrm{R}_{\mathrm{f}}}{\mathrm{R}_{\mathrm{f}}+\mathrm{R}_{\mathrm{g}}} \cdot\left[\frac{\mathrm{R}_{\mathrm{g}}}{\mathrm{R}_{\mathrm{f}}} \cdot \frac{\mathrm{l}_{\mathrm{c}}}{\mathrm{H}}+1\right]
$$

For the case of no air flow rate in the air gap:

$$
\eta=\frac{\mathrm{R}_{\mathrm{f}}}{\mathrm{R}_{\mathrm{f}}+\mathrm{R}_{\mathrm{g}}}
$$

The expression in (23) shows that there is always a fix relation between the two cases. As an example, in case of having no solar radiation, the relation between the transmission losses is constant.

For the case of very high air flow rate $\left(l_{c}>>0\right)$ in the air gap:

$$
\eta=\frac{\mathrm{R}_{\mathrm{f}}}{\mathrm{R}_{\mathrm{f}}+\mathrm{R}_{\mathrm{g}}} \cdot\left[\frac{\mathrm{R}_{\mathrm{g}}}{\mathrm{R}_{\mathrm{f}}}+1\right]=1
$$

This means that for very high air flow rates, the energy performance for the two cases, i.e a window with and without a curtain is the same, as at it was expected.

The total net heat gain (16) in an arbitrary room and for different air flow rates are studied and the result is illustrated in Figure 3. In this study, the solar intensity striking the window is assumed to be $800 \mathrm{~W} / \mathrm{m}^{2}$, dimensions of the curtain and window are

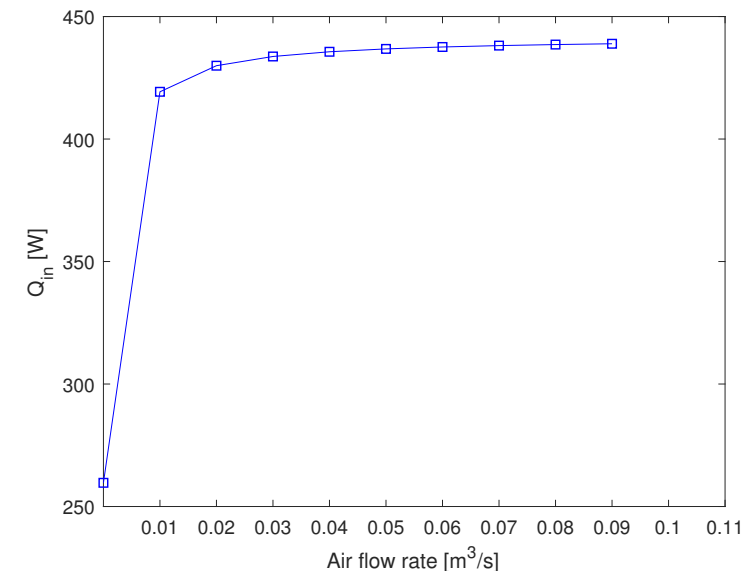

Figure 3: Graph showing the relation between the net heat gains in the room and the corresponding air flow rates in the air gap.

set to $[1.0 \mathrm{~m} \cdot 1.0 \mathrm{~m}]$, width of the air gaps are $10 \mathrm{~mm}$ each, absorptivity of the curtain is 0.9 and indoor and outdoor temperatures are set to be $20{ }^{\circ} \mathrm{C}$ and $0{ }^{\circ} \mathrm{C}$ respectively. The air flow rate varies in an interval between $0 \mathrm{~m}^{3} / \mathrm{s}$ and $1.0 \mathrm{~m}^{3} / \mathrm{s}$.

The study shows that for air flow rates higher than $0.1 \mathrm{~m}^{3} / \mathrm{s}$, the efficiency of the solar collector function and thus the total heat gain in the room is very much independent of the air flows created by fans. For air flows lower than $0.1 \mathrm{~m}^{3} / \mathrm{s}$, the magnitude of $\mathrm{Q}_{\text {in }}$ increases with increased air flow rate, up to 0.04-0.05 $\mathrm{m}^{3} / \mathrm{s}$. In other words, for the specific case studied here, increasing the air flow rate of the fans above $0.05 \mathrm{~m}^{3} / \mathrm{s}$ is considered to be unnecessary and should preferably be avoided. Worth to be mentioned is that in reality, and for an air gap of $10 \mathrm{~mm}$ in width, air flow rates higher than $0.1 \mathrm{~m}^{3} / \mathrm{s}$ are considered as unrealistically high flow rates.

Regarding the comparison between the two cases presented previously (21), i.e a window construction with and without a curtain and its solar collector function, the relation tends to always be less than or equal to 1. As it can be seen in Figure 4, the efficiency of the system with the Climate Curtain is never higher than the efficiency of only a window. In other words, the Climate Curtain and its solar collector can never utilize the surplus heat from solar radiation as good as a window without any curtain, where solar radiation can reach the indoor environment directly. The result shows also that having the Climate Curtain and its solar collector function, is more efficient for windows with lower height. The comparison is made for the same arbitrary room presented earlier but with a solar absorptivity of 1 for the curtain, i.e the absolutely best case scenario for the curtain.

\section{Case study- Forced convection}

To evaluate the energy performance of the Climate Curtain and its solar collector function, a steady state analysis for a case study of an arbitrary room, considered as a hot box is performed. In this room there 


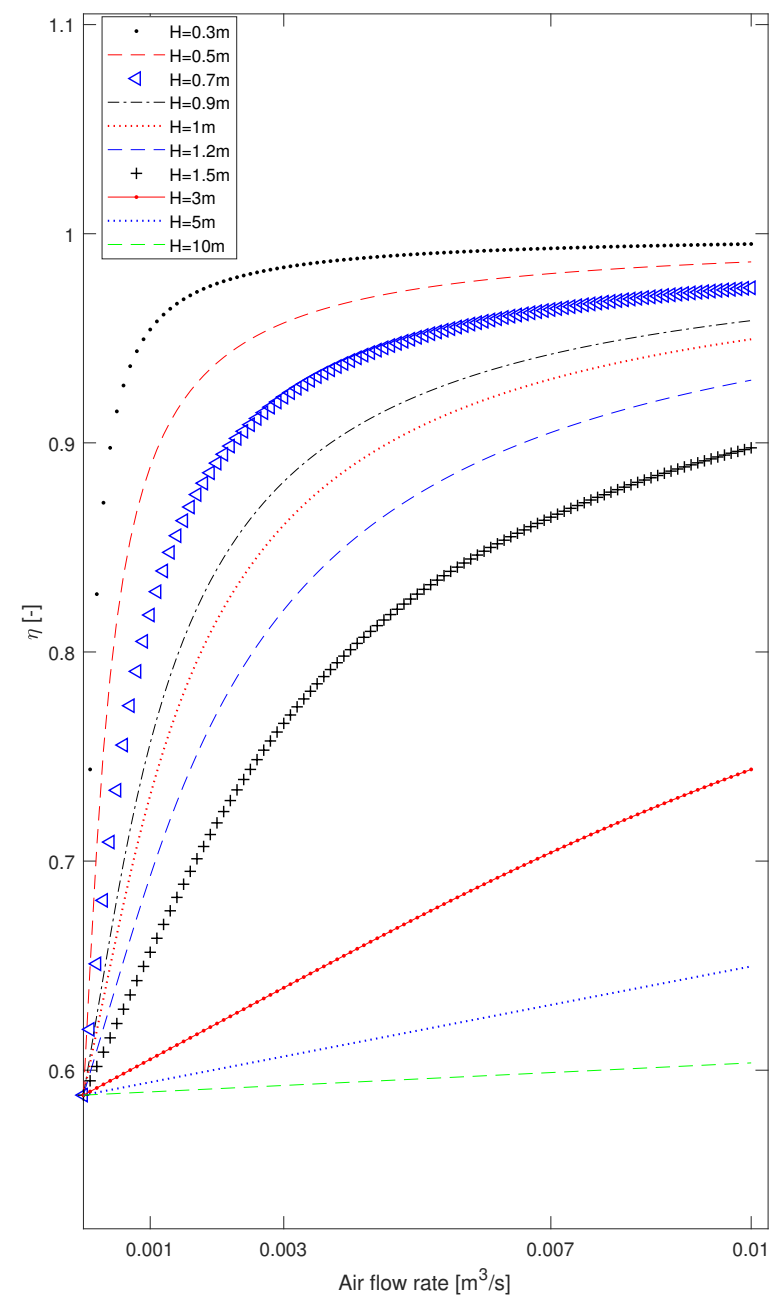

Figure 4: Graph showing the relation between the height of window and the efficiency of the solar collector function, for variable air flow rates.

is only one window, $[1 \mathrm{~m} \cdot 1 \mathrm{~m}]$. The g-value of the window is assumed to be 0.65 and the $\mathrm{U}$-value is 1.5 $\mathrm{W} / \mathrm{m}^{2} \mathrm{~K}$. All other parts of the building envelope are considered as adiabatic, i.e no other heat losses than the ones through the window are considered. The effect of thermal inertia of the building material, used in the room, is not considered, i.e steady state conditions. The absorptivity of the curtain is set to 0.9 and solar intensity is assumed to be $800 \mathrm{~W} / \mathrm{m}^{2}$. Indoor and outdoor temperatures are set to $20^{\circ} \mathrm{C}$ and $0{ }^{\circ} \mathrm{C}$ respectively.

In Table 1 the result of the analysis, for air flow rates between $0.001 \mathrm{~m}^{3} / \mathrm{s}$ and $0.05 \mathrm{~m}^{3} / \mathrm{s}$, are presented. As it can be seen, the difference between the heat gain for an air flow rate of $0.01 \mathrm{~m}^{3} / \mathrm{s}$ and the highest air flow rate of $0.05 \mathrm{~m}^{3} / \mathrm{s}$ is less than $5 \%$. It is worth mentioning that the power used to drive the fans in the curtain is of a magnitude of few Watts while the total net heat gain is about few hundreds of Watts.
Table 1: Results from the analysis performed for the case of forced convection and for variable air flow rate.

\begin{tabular}{|c|c|c|c|c|}
\hline $\mathrm{R}_{\mathrm{a}}\left[\mathrm{m}^{3} / \mathrm{s}\right]$ & $l_{\mathrm{c}}[\mathrm{m}]$ & $\mathrm{Q}_{\text {in.curtain }}[\mathrm{W}]$ & $\mathrm{Q}_{\text {in.window }}[\mathrm{W}]$ & $\eta[-]$ \\
\hline \hline $\mathbf{0 . 0 0 1}$ & 0.37 & 323 & 441 & 0.73 \\
\hline $\mathbf{0 . 0 0 5}$ & 1.87 & 400 & 441 & 0.90 \\
\hline $\mathbf{0 . 0 0 7}$ & 2.62 & 410 & 441 & 0.93 \\
\hline $\mathbf{0 . 0 1}$ & 3.74 & 419 & 441 & 0.95 \\
\hline $\mathbf{0 . 0 2}$ & 7.48 & 430 & 441 & 0.97 \\
\hline $\mathbf{0 . 0 3}$ & 11.22 & 434 & 441 & 0.98 \\
\hline $\mathbf{0 . 0 5}$ & 18.70 & 437 & 441 & 0.99 \\
\hline
\end{tabular}

\section{Case study- Natural convection}

Same model as for the case of forced convection is designed in MATLAB and solved by multiple iterations together with an initial guess value on the air flow rate. The only difference is that the air flow in the air gap is created by the pressure difference due to different temperatures in the curtain and indoor. Air flow rates and mean temperature in the air gap are calculated by (17), (18) and (19). The result of the analysis is presented in Table 2 .

Table 2: Results from the analysis performed for the case of natural convection.

\begin{tabular}{|c|c|c|c|c|}
\hline $\mathrm{R}_{\mathrm{a}}\left[\mathrm{m}^{3} / \mathrm{s}\right]$ & $\mathrm{l}_{\mathrm{c}}[\mathrm{m}]$ & $\mathrm{Q}_{\text {in.curtain }}[\mathrm{W}]$ & $\mathrm{Q}_{\text {in.window }}[\mathrm{W}]$ & $\eta[-]$ \\
\hline \hline $\mathbf{0 . 0 0 7 5}$ & 2.80 & 412 & 441 & 0.93 \\
\hline
\end{tabular}

As it can be seen, the net heat gain for a case of natural convection, i.e without any fans, has almost the same magnitude as for the case of forced convection.

\section{Conclusion}

The analytical analysis performed in this paper and the handy formulas presented show the impact of variable air flow rate on the energy performance of the Climate Curtain and its solar collector function. The advantage of the work is development of a relatively simple mathematical model allowing for energy analysis of this solution. The presented formulas can be used in energy analysis of similar vertical air gaps in building partitions and they are not necessarily limited to this specific type of curtain. Another advantage of the handy formulas presented are increased possibilities for combining analytical and numerical simulations and reduced computational time.

The analysis covers both forced convection, i.e when fans are installed in the curtain, but also natural convection. It should be noticed that the solutions presented in this paper overestimate the impact of the solar collector function of the curtain, when comparing the two cases of with and without curtain. It is assumed that all solar radiation striking the window and curtain is absorbed by the curtain, i.e the most optimal case for the curtain and its solar collector function. However, this will never be the case in a real case scenario. Beside that, also the fraction of 
solar radiation that is reflected and not absorbed by the curtain is not included in the analyses either.

It is shown that for the Climate Curtain and its solar collector function, the relation between the total net heat gain in the room and the air flow rate in the outermost layer of the curtain, i.e where air is heated by solar radiation and transferred to the interior, is rather weak. Increasing the air flow rate in the air gap seems to have a small positive effect up to a certain, quite low, value before starting to have no positive effect whatsoever. The optimal air flow rate is a case dependent parameter, but for most of windows, a small flow rate can be sufficient to optimize the performance of the solar collector function. In fact, for the case studied in this paper, the low air flow rate created by natural convection can be considered as sufficient for maximum utilization of the solar collector function. The comparison between the two cases of with and without a curtain and its solar collector function shows that a window system with a curtain will never be capable of utilizing the solar radiation as good as for a window system without a curtain. Concerning the energy performance of the Climate Curtain, the optimal case is to pull down the curtain and cover the window during nigh time and when the room is standing empty, and pull up the curtain during sunny hours of the day.

\section{Acknowledgment}

The paper presents the partly outcome of a collaborative research project between the division of Building Technology at Chalmers University of Technology and the Swedish company Climate Curtains AB. The support by the Climate Curtain AB is gratefully acknowledged.

\section{References}

Hagentoft, C.-E. (2001). Introduction to building physics. Studentlitterature.

Karim, A. (2018). Assessment and optimization of energy smart window curtains - A pilot study to evaluate the energy performance and a parametric study to optimize the design of the newly developed Climate Curtains. Master thesis, Gothenburg: Chalmers University of Technology.

Karim, A. N. and C. E. Hagentoft (2019). Experimental and modelling study of the energy performance of new types of energy smart window curtains (to be published).

Straube, J. (2002). Understanding and controlling air flow in building enclosures. Unviversity Waterloo.

Zhao, H.-x. and F. Magoulès (2012). A review on the prediction of building energy consumption. Renewable and Sustainable Energy Reviews 16(6), 35863592 . 